\title{
O Relacionamento em Redes no Campo Oncológico na Perspectiva dos Usuários
}

doi: https://doi.org/10.32635/2176-9745.RBC.2021v67n1.1119

\author{
Networking in the Oncology Field from the Perspective of Users \\ Redes en el Campo de la Oncología desde la Perspectiva de los Usuarios
}

William Messias Silva Santos ${ }^{\text {; }}$ Jaqueline Silva Santos²; Raquel Dully Andrade; Nadia Veronica Halboth ${ }^{4}$

RESUMO

Introduçáo: O diagnóstico e o tratamento de câncer podem ocasionar consequências traumáticas, tanto nos pacientes quanto nos seus familiares, que podem ser diminuídas por meio do apoio social. Objetivo: Identificar as percepçóes de apoio social de pacientes oncológicos de baixa renda. Método: Estudo descritivo com abordagem qualitativa fundamentado em aspectos conceituais do cuidado, realizado com pacientes oncológicos de baixa renda, assistidos por um núcleo de voluntários de um município do interior de Minas Gerais, seguindo os critérios do Consolidated Criteria for Reporting Qualitative Research. Para a coleta de dados, foram utilizadas entrevistas semiestruturadas gravadas, e o fechamento da amostra se deu pela técnica da saturação teórica. Os dados foram analisados com a utilização da análise temática indutiva. Resultados: $\mathrm{Na}$ análise dos dados, emergiram-se três unidades temáticas: relaçóes interpessoais: o suporte recebido de uma rede de colaboraçáo ativa entre pessoas; o cuidado singularizado como fonte de apoio da rede de saúde; e a religiosidade como forma de enfrentamento de situaçóes difíceis. Esses temas retratam aspectos relacionados à rede de apoio que podem contribuir para o cuidado integral ao paciente oncológico, com acolhimento e reconhecimento de necessidades. Conclusáo: Uma rede de apoio social sólida e constituída de pessoas que ocupam os mais diversos papeis sociais é percebida como importante para o melhor enfrentamento do câncer na ótica do modelo biopsicossocioespiritual.

Palavras-chave: Neoplasias; Apoio Social; Condições Sociais.

\begin{abstract}
Introduction: The diagnosis and treatment of cancer can cause traumatic consequences, both for patients and their families, which can be minimized through social support. Objective: To identify the perceptions of social support of low-income cancer patients. Method: Descriptive qualitative approach study based on conceptual aspects of care, carried out with lowincome cancer patients assisted by a group of volunteers from a city in the countryside of Minas Gerais, following the criteria of the Consolidated Criteria for Reporting Qualitative Research. For data collection, semistructured, recorded interviews were used, and the sample was closed using the theoretical saturation technique. The data were analyzed using inductive thematic analysis. Results: In the data analysis, three thematic units emerged: interpersonal relationships: the support received from an active collaboration network between people; singularized care as source of support for the health network; and religiosity as a way of coping with difficult situations. These themes portray aspects related to the support network that can contribute for the comprehensive care of the cancer patients, with welcoming and acknowledging needs. Conclusion: A solid social support network formed by individuals who play several social roles is perceived as important for better coping with cancer from the perspective of the biopsychosocio-spiritual model.
\end{abstract}

Key words: Neoplasms; Social Support; Social Conditions.

\section{RESUMEN}

Introducción: El diagnóstico y el tratamiento del cáncer pueden causar consecuencias traumáticas, tanto para los pacientes como para sus familias, que pueden reducirse mediante el apoyo social. Objetivo: Identificar las percepciones de apoyo social de pacientes con cáncer de bajos ingresos. Método: Estudio descriptivo con un enfoque cualitativo basado en aspectos conceptuales de la atención, realizado con pacientes con cáncer de bajos ingresos asistidos por un grupo de voluntarios de una ciudad en el interior de Minas Gerais, siguiendo los criterios del Consolidated Criteria for Reporting Qualitative Research. Para la recopilación de datos, se utilizaron entrevistas grabadas semiestructuradas y la muestra se cerró utilizando la técnica de saturación teórica. Los datos se analizaron mediante análisis temático inductivo. Resultados: En el análisis de los datos surgieron tres unidades temáticas: relaciones interpersonales: el apoyo recibido de una red de colaboración activa entre personas; la atención singularizada como fuente de apoyo a la red de salud; y la religiosidad como forma de afrontar situaciones difíciles. Estos temas representan aspectos relacionados con la red de apoyo que pueden contribuir a la atención integral de pacientes con cáncer, con necesidades acogedoras y de reconocimiento. Conclusión: una red sólida de apoyo social compuesta por personas que ocupan los roles sociales más diversos se percibe como importante para enfrentar mejor el cáncer en la perspectiva del modelo biopsicosocio-espiritual. Palabras clave: Neoplasias; Apoyo Social; Condiciones Sociales.

1,4Universidade Federal dos Vales do Jequitinhonha e Mucuri (UFVJM). Campus JK. Diamantina (MG), Brasil. E-mails: williammssantos@hotmail.com; nadiaveronicahalboth@gmail.com. Orcid iD: https://orcid.org/0000-0003-1197-5869; Orcid iD: https://orcid.org/0000-0002-9913-0491 2Universidade de São Paulo. Escola de Enfermagem de Ribeirão Preto (EERP/USP). Ribeirão Preto (SP), Brasil. E-mail: jaque_fesp@hotmail.com. Orcid iD: https:// orcid.org/0000-0002-7543-5522

3Universidade do Estado de Minas Gerais (UEMG). Campus Passos. Passos (MG), Brasil. E-mail: radully@gmail.com. Orcid iD: https://orcid.org/0000-0002-1515-098X Endereço para correspondência: William Messias Silva Santos. Rodovia MGT 367 - Km 583, 5000, Prédio da Faculdade de Medicina - Alto da Jacuba. Diamantina (MG), Brasil. CEP 39100-000. E-mail: williammssantos@hotmail.com 


\section{INTRODUÇÃO}

O diagnóstico de câncer pode ocasionar dúvidas e inseguranças tanto nos pacientes quanto nos seus familiares ${ }^{1}$. Destarte, tendo como base o modelo biopsicossocial no qual apresenta a saúde e a doença como condiçôes que estão em equilíbrio dinâmico codeterminadas por fatores biológicos, psicológicos e sociais que interagem, percebe-se a necessidade de o cuidado aos pacientes abranger essas três variáveis ${ }^{2}$.

O apoio social, também denominado suporte social, é definido como relaçóes interpessoais em que há a existência ou a disponibilidade das pessoas em confiar, demonstrar preocupação com o outro, valorizar, comunicar-se, ajudar e assistir com os recursos disponíveis ${ }^{3}$, nos quais há a possibilidade de envolver os colaboradores naturais (a família); os grupos informais (autoajuda) e os formais e institucionalizados, como as organizaçóes de doentes ${ }^{4}$. Nessa conjuntura, o apoio social tem potencial para moderar as consequências advindas do impacto do câncer, especificamente no que diz respeito aos sintomas depressivos e na qualidade de vida, proporcionando assim uma melhor recuperação e vivência de sua condição de saúde, o que poderá ocasionar melhor qualidade de vida, resgate da autoestima e da cidadania 5 .

Assim, o apoio social tem forte contribuição no auxílio às estratégias de enfrentamento ${ }^{6}$, na diminuição do nível de sofrimento psíquico ${ }^{7,8}$, da ansiedade em razão da aparência ${ }^{9}$ e, também, dos níveis de dor e de inflamação no pós-tratamento ${ }^{10}$. Por conseguinte, sendo a rede de apoio compreendida como um paradigma notável de promoçáo e recuperação da saúde, bem como de prevenção de doenças, é necessário proporcionar ao paciente oncológico um cuidado digno na sua realidade ${ }^{11}$, realizando assim açóes mais flexíveis, adaptando-as ao máximo ao contexto de cada paciente ${ }^{12}$ e almejando seu protagonismo ${ }^{13}$.

Considerando que o apoio social pode auxiliar no processo de adaptação e manutenção da qualidade de vida de pacientes com câncer, deve-se assumir que há a necessidade de identificar a conformaçáo da rede de apoio de que cada paciente dispóe, para que o cuidado seja planejado e implementado com qualidade ${ }^{14}$. Nesse cenário, o objetivo deste estudo foi identificar as percepçóes de apoio social de pacientes oncológicos de baixa renda.

\section{MÉTODO}

Estudo descritivo com abordagem qualitativa, fundamentado em aspectos conceituais do cuidado, compreendido como a dedicação ao outro, considerando-o em sua subjetividade ${ }^{15}$, realizado no município de Diamantina, Minas Gerais, Brasil, seguindo os critérios do Consolidated Criteria for Reporting Qualitative Research (COREQ) ${ }^{16}$.

Os participantes foram pacientes oncológicos de baixa renda, acompanhados por um Núcleo de Voluntários do município de Diamantina, que conta com uma equipe composta por pessoas da comunidade que buscam fornecer, principalmente, apoio financeiro a esses pacientes. Como critérios de inclusão, foram definidos: o paciente ter idade igual ou superior a 18 anos, ser cadastrado, e estar sendo acompanhado por esse Núcleo de Voluntários. Foram excluídos os pacientes que não tinham condiçóes de responder oralmente aos questionamentos realizados pelo pesquisador e/ou não foram encontrados após três tentativas no domicílio.

O refinamento do instrumento de coleta de dados elaborado ocorreu por meio de teste-piloto. Para a coleta de dados, foram utilizadas entrevistas semiestruturadas, gravadas, com duração de 40 a 90 minutos, realizadas pelo primeiro autor, sendo iniciadas com a questáo norteadora: "Como tem sido sua vida após o diagnóstico do câncer?". As entrevistas ocorreram por meio de visita domiciliar aos pacientes oncológicos assistidos pelo Núcleo de Voluntários nos meses de dezembro de 2019 a março de 2020.

Para o fechamento da amostra, utilizou-se a técnica da saturação teórica ${ }^{17}$. Os seguintes procedimentos foram seguidos: disponibilizaçáo dos registros dos dados (transcriçôes integrais e áudios gravados); exploração individual da entrevista para imersão em cada registro; compilaçáo dos tipos de enunciados identificados por meio de análises individuais de cada pesquisador, por entrevista; agrupamento dos tipos de enunciados correspondentes em cada categoria; codificação dos dados; alocação dos tipos de enunciados em uma tabela; constatação da saturação teórica em cada categoria; e visualização da saturação ${ }^{17}$. Com a realização desses procedimentos, a saturação teórica geral foi constatada na sétima entrevista. Destaca-se que náo houve recusa para participação neste estudo, sendo assim sete pacientes oncológicos de baixa renda foram denominados: E1, E2, E3..., E7.

A análise dos dados ocorreu com a utilização da análise temática indutiva, caracterizada por possibilitar a codificação embasada nos próprios dados qualitativos coletados $^{18}$. Nesse processo, identificaram-se três unidades temáticas, sendo: relaçôes interpessoais: o suporte recebido de uma rede de colaboração ativa entre pessoas; o cuidado singularizado como fonte de apoio da rede de saúde; e religiosidade como forma de enfrentamento de situações difíceis. Deve-se pontuar que não foi utilizado software para gerenciamento dos dados coletados.

A pesquisa foi aprovada pelo Comitê de Ética em Pesquisa da Universidade Federal dos Vales do 
Jequitinhonha e Mucuri, sob o número de parecer 3.229.421.

\section{RESULTADOS}

Em uma breve caracterização dos sete participantes da pesquisa, destaca-se que quatro eram mulheres e três eram homens com idades entre 26 anos e 87 anos, a maioria era católica, solteira, com filhos e renda familiar de um salário-mínimo.

O tempo transcorrido após o diagnóstico do câncer foi de um ano e dois meses a 20 anos, sendo que duas participantes tiveram recidiva, uma quando havia finalizado o tratamento oncológico e outra durante a radioterapia. A maior parte realiza tratamento oncológico em Belo Horizonte, sendo assistida pelo Núcleo de Voluntários há mais de um ano. Dos participantes da pesquisa, quatro foram diagnosticadas com câncer de mama, um com câncer de intestino, um com câncer de estômago e um com câncer de laringe.

\section{RELAÇÕES INTERPESSOAIS: O SUPORTE RECEBIDO DE UMA REDE DE COLABORAÇÃO ATIVA ENTRE PESSOAS}

A família é uma das principais fontes de apoio percebidas pelos participantes da pesquisa. Eles relatam a importância da presença, do estar ao lado deles para lutar contra o câncer:

É, ele [o sobrinho] dá, é o único que me dá confiança. Ele falou: "tia, eu vou chegar aí [...] nós vamos passear [...]". Uma vez, estávamos em uma festa grande lá [cidade onde reside o sobrinho], e ele estava comigo e falou: "tia, todo mundo aqui é testemunha, eu nunca na minha vida vou abandonar a senhora $[\ldots]$ ”. E nunca me abandonou, graças a Deus! (E1).

Ah, da família mesmo, alguns familiares, irmãos, entendeu!? O fato deles terem a vida deles, uma rotina bem pesada, fizeram-me acreditar que eles não fossem, não pudessem ser tão presentes, mas acabaram sendo. É bem importante essa parte do apoio em si (E5).

A presença de algum familiar para acompanhar o paciente durante o tratamento oncológico e o apoio financeiro, necessário em alguns momentos, foram destacados nos relatos:

Tem a minha filha que acompanha, aquela que tem o retrato ali, ó [mostra uma foto], ela me acompanha todo dia que eu vou, todo mês que eu vou (E2).

E tem um sobrinho meu, lá em Belo Horizonte [...], ele me ajudou demais (E7).
Os amigos foram outra fonte de apoio citada pelos participantes da pesquisa. Esse apoio, como também dos familiares, ocorre em diferentes momentos do diagnóstico e do tratamento oncológico, podendo ser traduzido na presença acolhedora, como relatado a seguir:

Tinha uma amiga comigo, a primeira vez [que recebeu o diagnóstico de câncer]. Foi muito importante, sinal que a gente não está sozinha, né!? Sinal que tem alguém. [...] Tive apoio dos meus amigos, tanto é que quem cortou o cabelo meu baixinho foi um amigo (E3).

As meninas [amigas] todas vêm aqui, vêm muito pouco, porque todas moram muito longe, $[\ldots]$ mas quando elas aparecem aqui, elas vêm me ver (E1).

A demonstração de apoio também pode ocorrer de outras formas. Muitas vezes, os amigos notam as necessidades da pessoa que está vivenciando uma situação difícil, como o enfrentamento do câncer e, assim, agem de forma a dar suporte e acolhimento, como apresentado nestas falas:

Eu tenho muita amizade [...]. Eu ganho muita coisa, graças a Deus! Ganho dinheiro lá de São Paulo mesmo, uma amiga manda para mim, essas vasilhas, foi ela que me deu. Ela manda muita coisa boa para mim de São Paulo. Ela manda dinheiro, mandou eu comprar as coisas... (E2).

[...] um monte de gente fez campanha para mim, nossa, me ajudaram demais da conta! Então eu acho que foi fundamental o apoio e ainda é. Até hoje eles me apoiam (E3).

Às vezes, eles trazem um doce, um biscoito, participam do tratamento da gente (E6).

Os vizinhos e os colegas de trabalho apareceram como figuras importantes, pois auxiliam na atenção a diferentes necessidades do paciente oncológico. Esse apoio pode se dar na forma financeira, no auxílio à execução de tarefas domésticas e na presença nos momentos difíceis, como apontados nos seguintes depoimentos:

Eu recebo um salário-mínimo, mas dá muito bem, porque os vizinhos ajudam-me, eu costumo achar banana na janela. Teve um dia que eu estava sem dinheiro para comprar um pão, coei o café e falei: "meu Deus do céu, o que é eu vou comer?". Quando eu olhei de baixo da porta, tinha dez reais. Eu falei: "Oh coisa boa!". Depois, em outro dia, eu achei cinco reais (E1).

Ajudam-me [vizinhos] muito. Algumas tarefas dentro de casa eu não posso fazer por causa do braço, aí eles vêm e fazem para mim, por exemplo, preparar a comida, arrumar a casa, lavar as roupas (E3). 
Tanto aqui na loja também, no período de tratamento que eu estava afastado, o pessoal [colegas de trabalho] foi bem presente e tal. Então é muito importante, faz bem (E5).

O papel desempenhado pelo Núcleo de Voluntários do município de Diamantina aparece nos relatos dos participantes como fonte de suporte emocional e financeiro:

Essa dona N. [líder do Núcleo] tem ajudado. Eu quero conhecê-la, eu não a conheço ainda. Ela é do coração bom (E7).

Aí eu fui e levei o resultado da biopsia, aí ela [líder do Núcleo] falou: "o que a gente puder te ajudar, a gente vai te ajudar". E realmente ajudam. [Risos] Quando têm exames que eu tenho que pagar, ela [líder do Núcleo] me ajuda, porque do INSS eu não estou recebendo nada. [...] Ajudam demais da conta, tanto financeiramente quanto com as visitas das duas [integrantes do Núcleo], elas vêm direto aqui em casa. A gente também está conversando no WhatsApp (E3).

Conforme observado nessa unidade temática, o apoio recebido de uma rede sustentadora de pessoas, composta por familiares, amigos, vizinhos, colegas de trabalho e comunidade, pode favorecer sentimentos de aceitação e acolhimento.

\section{CUIDADO SINGULARIZADO COMO FONTE DE APOIO DA REDE DE SAÚDE}

As experiências vivenciadas em diferentes pontos da rede de atenção à saúde podem ser entendidas como momentos de apoio ao paciente oncológico. Houve relatos de satisfação com a assistência hospitalar recebida:

Para mim, tanto faz, nos dois [hospitais], eu fui bem atendido, bem tratado, não posso queixar de nenhum dos dois, náo. [...] Todos os dois me fizeram bem (E6).

É ótimo! Eles abraçam a gente mesmo assim, sabe? Eles assim... eu náo tenho de reclamar de nada, eu sou suspeita para poder falar. [Risos] Eu gosto, nossa, eu fiquei apaixonada. [...] $\mathrm{O}$ pessoal, todo mundo, sabe, não trata ninguém com indiferença, todo mundo lá, para eles, é igual, da recepção até o pessoal que limpa, os enfermeiros. Entáo eu gosto muito de lá (E3).

A importância da abordagem acolhedora dos profissionais de saúde, com reconhecimento das necessidades biopsicossociais do paciente oncológico, apareceu nos relatos:
Muito bom, muito contato, uma preocupação enorme deles [dos médicos] com a gente. Consideram desde o físico do corpo da gente até o psicológico. Eles cuidam muito disso também. Visam muito o psicológico das pessoas (E5).

Um dos enfermeiros lá de Montes Claros é meu amigo até hoje. Ele e outra enfermeira, também lá dentro [hospital], me ajudam até hoje (E3).

Esse apoio também emerge na relação médico-paciente, na qual há escuta ativa, linguagem acessível e atitude empática, conforme apontam os relatos:

É com o médico, para ele eu conto tudo, e ele conversa comigo muito tempo lá, me dá orientaçóes (E2).

Mas ela [a médica] me tranquilizou demais, nas duas vezes, graças a Deus! (E3).

Eu perguntava, "está acontecendo isso", aí ele [o médico] falava: "isso é normal, é do tratamento mesmo". Porque, às vezes, você passa a sentir algo que não sentia, aí você pergunta e ele explica (E6).

Durante o tratamento do câncer, além dos profissionais de saúde, o paciente pode ter contato com pessoas que estão vivenciando situaçóes semelhantes, o que possibilita o estabelecimento de um vínculo afetivo. Isso pode ocorrer, por exemplo, nas casas de apoio, como constatou uma participante da pesquisa:

Nossa, era uma maravilha! [Risos] Era uma bagunça. [Risos] Era ótimo, igual família mesmo, não tinha briga nenhuma nem nada. Era muita brincadeira, tinha um refeitório, todo mundo sentava junto para poder fazer as refeiçóes. À noite, a gente ia brincar de baralho, assistir TV, assistir filme, ia ao cinema, porque é muito pertinho do shopping, entáo juntava a galera toda e íamos ao cinema. Ah, era ótimo! [Risos] Uma maravilha, a minha convivência com eles (E3).

\section{RELIGIOSIDADE COMO FORMA DE ENFRENTAMENTO DE SITUAÇÕES DIFÍCEIS}

$\mathrm{Na}$ religiosidade, muitos encontram uma fonte de apoio para os momentos de dificuldades enfrentados durante o tratamento oncológico:

Nossa, dá uma força gigante. Divino Pai Eterno e Nossa Senhora Aparecida que me ajudaram a enfrentar o câncer. Jesus está lá no meu quarto, um quadro assim, ó [mostra o tamanho] (E2).

Alguns relatam o fortalecimento da relação com a divindade na qual acredita: 
"Pelo contrário, eu confiei mais em Deus do que antes" (E7); a confiança que têm na divindade: "Que nós, sem Deus, não vivemos né!?" (E4); e o agradecimento pela vida que têm: "Não, não vou à missa, não, mas eu rezo muito, tudo eu rezo, toda noite, têm os agradecimentos por eu morar aqui, pelos vizinhos me ajudarem, pelas pessoas me darem apoio, toda noite tem a ladainha" (E1).

Assim, contar com diferentes tipos de apoio pode emergir como um fator de proteçáo importante para o enfrentamento do câncer:

Ah, foi fundamental. Eu acho que foi fundamental, viu?! Fundamental, fundamental, esse apoio que eu tive. Porque, se a gente não tem apoio, a gente não tem motivo para poder seguir (E3).

\section{DISCUSSÃO}

Sabendo-se que o apoio social é oriundo das redes de relaçóes sociais formais que se originam das posiçóes e dos papéis desempenhados na sociedade e pelas relaçôes sociais informais, nas quais a ligação ocorre em virtude do parentesco ou do envolvimento afetivo ${ }^{19}$, percebe-se que as relaçóes sociais estão presentes na vida das pessoas e podem se modificar ao longo dos anos ${ }^{20}$.

Assim, a família se constitui como uma fonte de apoio fundamental e acaba por necessitar também de uma rede de suporte para desempenhar esse papel, tendo em vista que os familiares mais envolvidos nesse contexto tendem a precisar se equilibrar emocionalmente e em suas atividades diárias. Essa situação, muitas vezes, exige melhor organização temporal e financeira, compondo uma fase de grande demanda aos familiares, de forma que qualquer apoio ao paciente representa também um apoio ao familiar e vice-versa. Assim, a rede de apoio formada por vizinhos, amigos e colegas de trabalho tem grande relevância e favorece em muito o processo de adaptabilidade à fase de enfrentamento do diagnóstico e tratamento, como apontaram os resultados deste estudo, o que pode impactar positivamente no prognóstico.

A rede de apoio social deve ser reconhecida como parte do contexto comunitário, com potencial de influenciar a funcionalidade e a organização dentro das famílias, sendo altamente benéfica a formaçáo e/ou o cultivo de uma cultura de cooperação entre família e comunidade, que pode produzir resultados de proteçáo aos seus membros, especialmente relevante em situações de maior vulnerabilidade social ${ }^{20}$.

No mundo contemporâneo, onde as pessoas de modo geral tendem a ter carga alta de atividades e disponibilidade de tempo reduzida para prestar apoio, os vizinhos desempenham um papel muito relevante por estarem mais próximos e, assim, terem maior facilidade de identificar uma necessidade e, também, por ficarem mais facilmente ao alcance da pessoa e da família que demanda apoio. Os vizinhos podem representar um importante mediador entre o paciente e a família, ou entre o paciente e o serviço de saúde, facilitando a identificação de um problema precocemente e viabilizando o encaminhamento a alguém ou a algum órgão que possa atender à necessidade apresentada. É benéfico que isso seja estimulado no ambiente comunitário, como nas escolas, igrejas e serviços de saúde, especialmente na Estratégia Saúde da Família (ESF), que tem como uma de suas premissas o vínculo com a comunidade.

Os vizinhos são atores importantes na rede de apoio social, promovendo elevaçáo no nível de bem-estar, segurança e qualidade de vida dos sujeitos que têm oportunidade de serem beneficiados por essa rede, favorecendo sentimento de pertencimento e confiança ${ }^{21}$.

A ESF atua na proposição, organizaçáo e integraçáo das açôes de saúde em um território definido, a partir de uma atenção centrada na família, considerando seu entorno físico e social, proporcionando uma compreensão ampliada do processo saúde-doença e das possibilidades de intervenções e interaçōes ${ }^{21,22}$. Além disso, quando as equipes de saúde se aproximam das famílias, pode haver a criação de processos dialógicos e de confiança que possibilitem a exteriorização de preocupaçôes e o esclarecimento de dúvidas ${ }^{23}$.

Quando o paciente oncológico é oriundo de uma família em situação de pobreza, o apoio social é ainda mais relevante ${ }^{24}$. Nessa perspectiva, emerge o apoio fornecido por voluntários e órgãos sociais que, de forma empática, buscam ajudar quem está vivenciando uma situação difícil. Assim, são necessários o reconhecimento e a dignificação do trabalho e do valor das aprendizagens que emergem nessa prática, tornando mais visível essa atividade como parte integrante e importante da rede ${ }^{25}$.

Foi relevante notar, em algumas falas, alternativas encontradas pela rede de apoio para oferecer suporte a algumas necessidades materiais, comuns em contextos de baixa renda, como deixar algum alimento ou valor em dinheiro na janela ou por debaixo da porta. Esses exemplos podem ilustrar a afirmação da relação entre o aumento do suporte social recebido com o aumento da qualidade das relaçôes sociais, da autoestima, da satisfação da vida e do sentimento de comunidade ${ }^{26}$.

Os relatos mostraram ter sido fundamental esse suporte em alguns momentos. Esses achados apontam que poderia ser relevante estimular a comunidade a encontrar caminhos alternativos e criativos para prestar apoio a quem precisa. Isso poderia ser encorajado de diversas maneiras 
na comunidade, como por meio das redes sociais, em rádios, jornais, igrejas e de cartazes em unidades de saúde de atenção primária e secundária, entre outros.

Os colegas de trabalho também se mostraram importantes na rede de apoio. Algumas vezes, esse apoio pode emergir como auxílio financeiro ${ }^{27}$. Outro aspecto relevante evidenciado é a importância desse apoio para os familiares dos pacientes, que podem precisar se ausentar do trabalho em alguns momentos para o acompanhamento, e poderão fazer isso com maior tranquilidade quando recebem compreensão, acolhimento e suporte no seu ambiente de trabalho. Reforça-se que o acesso a melhores condiçóes emocionais por parte dos familiares cuidadores nessa etapa tende a reverberar em melhor funcionamento da família na fase de enfrentamento da doença, maior bem-estar e qualidade de vida para o paciente e melhores resultados no tratamento.

Sabe-se que apoio social no trabalho proporciona maiores níveis de satisfação dos trabalhadores na realização das suas atividades laborais ${ }^{28}$. Além disso, ele está relacionado à interação cooperativa entre colegas e chefias, contribui para a redução do desgaste do trabalhador e dos riscos à saúde, entre muitos outros benefícios importantes para o ser humano inserido na vida em sociedade. Desse modo, os elementos ligados ao apoio social devem ser estudados e receber atenção para que sejam reconhecidos, valorizados e promovidos em uma busca por interaçóes humanas e produtivas no ambiente de trabalho ${ }^{29}$.

Muito importante se mostrou também o apoio formal representado pelos profissionais de saúde, especialmente no que se refere à qualidade da comunicação durante as interaçóes, à humanização no atendimento e ao cuidado holístico integral não centrado apenas na doença e nos sinais e sintomas. Destarte, os profissionais de saúde devem buscar realizar um cuidado particularizado que proporcione atenção às necessidades do paciente oncológico $^{30}$.

Ademais, pode ser praticado o advocacy do paciente, entendido como sua defesa pelo profissional de saúde, processo permeado por empatia, priorização da saúde e proteçấo dos direitos do paciente ${ }^{31}$.

No sentido dessa atenção integral e humanizada como componente fundamental da rede de apoio, é importante que se volte o olhar para os processos de trabalho, valorizando o saber e a contribuição tanto de profissionais quanto de usuários na construção desse processo, reconhecendo o valor do trabalho em equipe $\mathrm{e}$ de uma abordagem intersetorial, com inserçáo em rede ${ }^{32}$.

Mostrou-se também essencial como elemento protetor e fortalecedor a vivência da espiritualidade, contribuindo para melhores níveis de bem-estar, confiança e coragem. Compreende-se espiritualidade como um questionamento sobre o sentido de viver e de estar no mundo, em que não é preciso haver a existência de um Deus ou de religiosidade, como a crença em algo divino e práticas relacionadas a uma doutrina na qual a base é a fé3 ${ }^{\prime 3}$.

A espiritualidade age como fator protetor contra sintomas psíquicos oriundos de uma doença ${ }^{34}$. Destarte, por se mostrar influenciadora no processo saúde-doença, a espiritualidade deve estar contemplada em uma abordagem holística na assistência ao indivíduo, de modo que a discussão desse elemento deve estar incluída na formação dos profissionais da área de saúde, o que pode contribuir para o desenvolvimento de futuros profissionais, para que estejam mais sensíveis e habilidosos para acolher, compreender e dar suporte às necessidades dos sujeitos ${ }^{35}$.

Considera-se, neste estudo, diante do cenário exposto, que uma rede de apoio com elevado grau de efetividade é um diferencial importante para a melhoria da qualidade de vida ${ }^{36}$ e para a busca de estratégias de enfrentamento ${ }^{37}$ mais adequado de dificuldades ao longo do ciclo de vida, especialmente em situaçóes de vulnerabilidade. Para isso, são importantes a interação, o reconhecimento e o fortalecimento mútuo entre os pontos de apoio da rede, bem como a apreciação e a retroalimentação coletiva dentro dela.

\section{CONCLUSÃO}

Por meio deste estudo, é possível notar a importância de uma rede de apoio social sólida e constituída de pessoas que ocupam os mais diversos papéis sociais no melhor enfrentamento do câncer dentro da ótica do modelo biopsicossocioespiritual.

Além disso, observa-se a importância de um profissional de saúde que náo esteja apenas capacitado para tratar a doença, mas também o paciente com suas particularidades. Daí a necessidade de o profissional de saúde realizar um cuidado mais humanizado e atento, que pratique a escuta ativa, tenha empatia e respeito.

Embasado nessa concepçáo, acredita-se que é preciso abordar, já durante a graduação nos cursos de saúde, a visão ampliada do paciente, o cuidado integral, a forma de se comunicar, que possibilite ao receptor do diálogo entender o que o profissional de saúde está falando e a prática de educação em saúde e de advocacy do paciente.

Por fim, espera-se que este estudo incentive e contribua com novas pesquisas que identifiquem e avaliem as redes de apoio social dos pacientes oncológicos em outros contextos, visto que, embora os subsídios deste estudo sejam relevantes para os estudantes e profissionais da área da saúde, devem ser avaliados com cautela, porquanto envolvem uma amostra peculiar de pacientes oncológicos. 


\section{CONTRIBUIÇÕES}

William Messias Silva Santos e Nadia Veronica Halboth contribuíram substancialmente na concepção e planejamento do estudo; na obtenção, análise e interpretação dos dados; e na redação. Jaqueline Silva Santos e Raquel Dully Andrade contribuíram substancialmente na redação e revisão crítica. Todos os autores aprovaram a versão final publicada.

\section{DECLARAÇÃO DE CONFLITO DE INTERESSES}

Nada a declarar.

\section{FONTES DE FINANCIAMENTO}

Não há.

\section{REFERÊNCIAS}

1. Ferreira AS, Bicalho BP, Neves LFG, et al. Prevalência de ansiedade e depressão em pacientes oncológicos e identificaçáo de variáveis predisponentes. Rev Bras Cancerol. 2016;62(4):321-8. doi: https://doi. org/10.32635/2176-9745.RBC.2016v62n4.159

2. Pereira TTSO, Barros MNS, Augusto MCNA. O cuidado em saúde: o paradigma biopsicossocial e a subjetividade em foco. Mental. 2011;9(17):523-36.

3. Fonseca ISS, Moura SB. Apoio social, saúde e trabalho: uma breve revisão. Psicol Am Lat. 2008;(15).

4. Canesqui AM, Barsaglini RA. Apoio social e saúde: pontos de vista das ciências sociais e humanas. Ciênc Saúde Coletiva. 2012;17(5):1103-14. doi: http://doi. org/10.1590/S1413-81232012000500002

5. Sette CP, Capitão CG. Efeito moderador do suporte social em pacientes oncológicos. Psic, Saúde \& Doenças. 2018;19(2):265-77. doi: http://doi. org/10.15309/18psd190209

6. Hoseini L, Kashani FL, Akbari S, et al. Model development of illness perception and consequences in breast cancer patients. Asian Pac J Cancer Prev. 2016;17(S3):185-90. doi: http://doi.org/10.7314/ apjcp.2016.17.s3.185

7. Wang F, Liu J, Liu L, et al. The status and correlates of depression and anxiety among breast-cancer survivors in Eastern China: a population-based, cross-sectional casecontrol study. BMC Public Health. 2014;14:326. doi: http://doi.org/10.1186/1471-2458-14-326

8. Ng CG, Mohamed S, See MH, et al. Anxiety, depression, perceived social support and quality of life in Malaysian breast cancer patients: a 1-year prospective study. Health Qual Life Outcomes. 2015;13:205. doi: http://doi. org/10.1186/s12955-015-0401-7
9. Ozkaraman A, Culha I, Fadiloglu ZC, et al. Relationships between social support and social image concerns in Turkish women with breast cancer. Asian Pac J Cancer Prev. 2015;16(5):1795-802. doi: http://doi.org/10.7314/ apjcp.2015.16.5.1795

10. Hughes S, Jaremka LM, Alfano CM, et al. Social support predicts inflammation, pain, and depressive symptoms: longitudinal relationships among breast cancer survivors. Psychoneuroendocrinology. 2014;42:38-44. doi: http:// doi.org/10.1016/j.psyneuen.2013.12.016

11. Ferreira PC, Wakiuchi J, Baldissera VDA, et al. Sentimentos existenciais expressos por usuários da casa de apoio para pessoas com câncer. Esc Anna Nery. 2015;19(1):66-72. doi: http://doi.org/10.5935/14148145.20150009

12. Mufato LF, Araujo LFS, Bellato R, et al. Mediação nas redes para o cuidado de pessoa e família que vivencia o câncer colorretal. Texto Contexto Enferm. 2013;22(2):407-15. doi: http://doi.org/10.1590/S010407072013000200017

13. Santos JS, Maia MAC, Andrade RD, organizadores. Promoçáo da saúde: um olhar para diferentes cenários. Sáo Paulo: Cia do eBook; c2019. [Capítulo, 7], Santos WMS, Lima SP, Costa GAB, et al. Promoção da saúde da mulher acometida pelo câncer de mama: reflexão teórica; p. [ePUB, 742KB].

14. Kolankiewicz ACB, Souza MM, Magnago TSBS, et al. Apoio social percebido por pacientes oncológicos e sua relação com as características sociodemográficas. Rev Gaúcha Enferm. 2014;35(1):31-8. doi: https://doi. org/10.1590/1983-1447.2014.01.42491

15. Carnut L. Cuidado, integralidade e atenção primária: articulação essencial para refletir sobre o setor saúde no Brasil. Saúde Debate. 2017;41(115):1177-86. doi: https://doi.org/10.1590/0103-1104201711515

16. Tong A, Sainsbury P, Craig J. Consolidated Criteria for Reporting Qualitative Research (COREQ): a 32-item checklist for interviews and focus groups. Int J Qual Health Care. 2007;19(6):349-57. doi: https://doi. org/10.1093/intqhe/mzm042

17. Fontanella BJB, Luchesi BM, Saidel MGB, et al. Amostragem em pesquisas qualitativas: proposta de procedimentos para constatar saturação teórica. Cad Saúde Pública. 2011;27(2):389-94. doi: https://doi. org/10.1590/S0102-311X2011000200020

18. Souza LK. Pesquisa com análise qualitativa de dados: conhecendo a análise temática. Arq Bras Psicol. 2019;71(2):51-67. doi: http://doi.org/10.36482/18095267.ARBP2019v71i2p.51-67

19. Rosa TEC, Benício MHDA. As redes sociais e de apoio: o conviver e a sua influência sobre a saúde. BIS, Bol Inst Saúde. 2009;(47):80-3.

20. Seibel BL, Falceto OG, Hollist CS, et al. Rede de apoio social e funcionamento familiar: estudo longitudinal 
sobre famílias em vulnerabilidade social. Pensando Fam. 2017;21(1):120-36.

21. Silocchi C, Junges JR, Fernandes AA. Rede de apoio social: identificação, reconhecimento e integraçáo com a fisioterapia comunitária. Sanare. 2016;15(2):78-86.

22. Macinko J, Mendonça CS. Estratégia saúde da família, um forte modelo de Atenção Primária à Saúde que traz resultados. Saúde Debate. 2018;42(n. spe 1):18-37. doi: http://doi.org/10.1590/0103-11042018s102

23. Ångström-Brännström C, Engvali G, Mullaney T, et al. Children undergoing radiotherapy: swedish parents' experiences and suggestions for improvement. PLoS One. 2015;10(10):e0141086. doi: https://doi.org/10.1371/ journal.pone.0141086

24. Sanchez KOL, Ferreira NMLA. O apoio social para a família do doente com câncer em situação de pobreza. Texto contexto Enferm. 2012;21(4):792-9. doi: https:// doi.org/10.1590/S0104-07072012000400009

25. Rego R, Zózimo J, Correia MJ. Voluntariado em Portugal: do trabalho invisível à validação de competências. Sociologia, Problemas e Práticas. 2017;(83):75-97. doi: http://doi.org/10.7458/SPP2017836498

26. Elvas S, Moniz MJV. Sentimento de comunidade, qualidade e satisfação de vida. Aná Psicológica. 2010;28(3):451-64.

27. Gage-Bouchard EA, LaValley S, Panagakis C, et al. The architecture of support: the activation of preexisting ties and formation of new ties for tailored support. Soc Sci Med. 2015;134:59-65. doi: https://doi.org/10.1016/j. socscimed.2015.04.003

28. Fonseca ISS, Araújo TM, Bernardes KO, et al. Apoio social e satisfação no trabalho em funcionários de uma empresa de petróleo. Psicol Am Lat. 2013;25:43-56.

29. Godinho MR, Ferreira AP, Moura DCA, et al. Apoio social no trabalho: um estudo de coorte com servidores de uma universidade pública. Rev Bras Epidemiol. 2019;22:e190068. doi: http://doi.org/10.1590/1980549720190068

30. Zhang H, Xiao L, Ren G. Experiences of social support among chinese women with breast cancer: a qualitative analysis using a framework approach. Med Sci Monit. 2018;24:574-81. doi: https://doi.org/10.12659/ MSM.908458

31. Davoodvand S, Abbaszadeh A, Ahmadi F. Patient advocacy from the clinical nurses' viewpoint: a qualitative study. J Med Ethics Hist Med. 2016;9:5.

32. Ferreira LR, Artmann E. Discursos sobre humanização: profissionais e usuários em uma instituição complexa de saúde. Ciênc Saúde Colet. 2018;23(5):1437-50. doi: https://doi.org/10.1590/1413-81232018235.14162016

33. Murakami R, Campos CJG. Religião e saúde mental: desafio de integrar a religiosidade a cuidado com o paciente. Rev Bras Enferm. 2012;65(2):361-7. doi: https://doi.org/10.1590/S0034-71672012000200024
34. Jaramillo RG, Monteiro PS, Borges MS. Coping religioso/espiritual: um estudo com familiares de crianças e adolescentes em tratamento quimioterápico. Cogitare Enferm. 2019;24:e62297. doi: https://doi.org/10.5380/ ce.v24i0.62297

35. Reginato V, Benedetto MAC, Gallian DMC. Espiritualidade e saúde: uma experiência na graduação em medicina e enfermagem. Trab Educ Saúde. 2016;14(1):237-55. doi: http://doi.org/10.1590/19817746-sip00100

36. Yan B, Yang LM, Hao LP, et al. Determinants of quality of life for breast cancer patients in Shanghai, China. PLoS One. 2016;11(4):e0153714. doi: http://doi. org/10.1371/journal.pone.0153714

37. Hoseini L, Kashani FL, Akbari S, et al. Model development of illness perception and consequences in breast cancer patients. Asian Pac J Cancer Prev. 2016;17(S3):185-90. doi: http://doi.org/10.7314/ APJCP.2016.17.S3.185 